Discussion Papers of the

Max Planck Institute for

Research on Collective Goods

2020/2

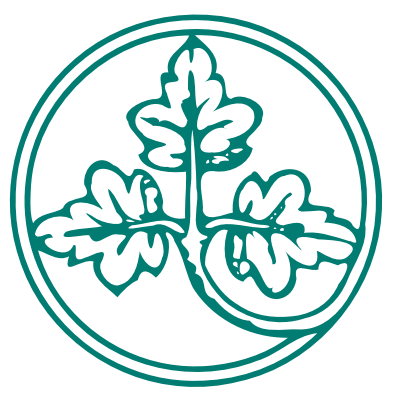

Property is Dummy Proof:

An Experiment

Oren Bar-Gill

Christoph Engel 


\title{
Property is Dummy Proof: An Experiment
}

\author{
Oren Bar-Gill / Christoph Engel
}

January 2020 


\title{
Property is Dummy Proof: An Experiment
}

\author{
Oren Bar-Gill \& Christoph Engel*
}

\begin{abstract}
Law is for humans. Humans suffer from cognitive limitations. Legal institutions can help humans by making these limitations irrelevant. This experiment shows that strong property rights serve this function. In theory, efficient outcomes obtain even without strong property rights. In a hypothetical world where cognitive ability is perfect, individuals would not engage in wasteful taking wars. A party would not take another's good, if she expects that the good will ultimately be taken back. By contrast, the large majority of experimental subjects takes a token good when interacting with a computer they know to maximize profit, and that has a symmetric ability to take the good back. Experience mitigates the inefficiency, but does not eliminate it; and in the real world relevant experience is often lacking. We show that cognitive limitations prevent weak property rights - imperfectly enforced property rules and liability rules with low damages - from securing efficient outcomes. Strong property rights should be preferred, because they are dummy proof.
\end{abstract}

JEL: C91, D02, D47, D61, K11

Keywords: Property, Liability, Cost of Appropriation, Cognitive Limitations, Sophistication, Descriptive and Normative Beliefs

Oren Bar-Gill, Harvard Law School, bargill@law.harvard.edu. Christoph Engel, Max Planck Institute for Research on Collective Goods, engel@coll.mpg.de. The experiment has been funded from the regular budget of the Max Planck Institute for Research on Collective Goods in Bonn, Germany. The experiment has received IRB approval from the Ethics Council of the Max Planck Society. Helpful comments by Pascal Langenbach, Eugenio Verrina, and audiences at the University of Vienna and at the Max Planck Institute for Research on Collective Goods are gratefully acknowledged. 


\section{Introduction}

Should an entitlement be protected with a strong property rule or rather with a weaker liability rule? A large literature in law and economics has studied this question; and the debate rages on (see Calabresi and Melamed 1972, Kaplow and Shavell 1996, Bebchuk 2001, Ayres 2005, Bar-Gill and Bebchuk 2010, Bar-Gill and Persico 2016, Bar-Gill and Persico 2019). One important critique of liability rules, especially when the cost of taking is small, is that a lowvaluation party might inefficiently take from a high-valuation party. The concern is two-fold: (1) the asset might end up in the hands of a low-valuation user (an allocative efficiency concern), and (2) wasteful taking costs might be incurred. In this project we focus on the second.

Of course, with no bargaining costs and symmetric information, Coasean bargaining would prevent such an inefficient outcome. In earlier work, we have tested the limits of Coasean bargaining, both in the complete absence of property rights (Bar-Gill and Engel 2016), and when property rights are protected by liability rules with different levels of damages for taking (Bar-Gill and Engel 2018). But even in the absence of Coasean bargaining, an inefficient outcome can be avoided. If a rational taker anticipates that the original owner would take back the asset, then she may decide not to take in the first place, especially if taking is not free of charge. Why incur a taking cost, if you don't expect to keep the asset? Sequential takings have been studied in the theoretical literature (see Calabresi and Melamed 1972, Kaplow and Shavell 1996, Bebchuk 2001, Ayres 2005, Bar-Gill and Bebchuk 2010, Bar-Gill and Persico 2016, Bar-Gill and Persico 2019). In this paper, we use an experiment to assess the ability of sequential takings to secure efficiency.

The protective effect of the threat of a retaking requires rationality, specifically the ability to look ahead, anticipate future takings and calculate their implications for the present decision whether or not to take the asset. This requirement may be demanding, especially if multiple rounds of taking (and retaking) are possible. Moreover, rationality (in this sense) must be common knowledge. Yet experimental studies have shown that thinking ahead is hard - that most people can think only a few steps ahead (Bosch-Domenech, Montalvo et al. 2002, Kübler and Weizsäcker 2004, Crawford and Iriberri 2007, Sbriglia 2008). ${ }^{1}$ And theoretical work has modeled such level-k reasoning (see Nagel 1995, Stahl and Wilson 1995, Arad and Rubinstein 2012a, Arad and Rubinstein 2012b). ${ }^{2}$

We study the relationship between rationality and efficiency when taking is costly and the cost of taking is common knowledge. In a classic liability regime, the cost of taking is a transfer. If she decides to take, the taker is obliged to pay the legally defined amount of

1 For more references, see the lit review in the hypothesis section.

2 Level k models allows for players with different levels of sophistication: Level-0 players make uniform choices based on a simple decision rule; Level-1 players are more sophisticated, choosing the optimal strategic response to Level-0 players; Level-2 players are able to choose the best response to Level-1 players' strategy and so forth. The experimental investigation found that subjects rarely think more than 3 steps ahead (or, more accurately, the experimental results were consistent with subjects using Level3 reasoning at most). To be precise, the level-k reasoning model measures the "depth" of reasoning in a simultaneous-move game, which is related, but not identical to the "thinking ahead" notion in our dynamic takings game. 
compensation to the original owner. This transfer raises additional behavioral concerns that we have tested in earlier work. In this paper, we bracket these additional concerns and focus on taking costs that are not transfers. A legally-imposed fine is an example. Another example is "technological" taking cost - when the original owner protected the good (with locks, walls or firewalls) and the taker must incur a cost to overcome these protective measures. A third example involves customization: the original owner may have customized the good for a particular use and the taker, if she intends a different use, must incur her own customization costs.

Note that taking might occur, and these taking costs might be incurred, only when property rights are weak. And property rights are weak, when they are protected by an imperfectly enforced property rule or by a liability rule with low damages that might also be imperfectly enforced. Imperfect enforcement is common. Budget-constrained prosecutors tend to focus on serious crime, not on the theft (taking) of small-value items. Even for higher-value assets, like cars, prosecution rates are small. And owners who had their assets taken might not bring a lawsuit, if the economic value of the stolen item is small relative to the cost of litigation.

If the cost of taking is sufficiently small, there may be multiple rounds of taking. The taker takes, the original owner takes back, the taker takes again, and so on, until one party has no more money to fund a taking (or retaking). (When taking costs are transfers, the damages paid by one agent can be used by the other agent to fund additional rounds of taking and retaking. We abstract from this possibility by focusing on taking costs that are not transfers.) When agents are fully rational much taking is avoided, as the agent anticipates that retaking, and perhaps several rounds of taking and retaking, will leave her without the good and having wasted resources on futile takings (and retakings). But when agents are boundedly rational (in the sense of limited foresight), socially wasteful taking costs might be incurred and inefficient taking might be observed. This is indeed what we find. Since strong property rights guarantee efficiency regardless of the parties' sophistication, ${ }^{3}$ these findings favor "dummy proof" strong property rights.

In our experiment, one human participant interacts with a computer known to maximize profit. This design choice allows us to bracket all the behavioral effects that are triggered by the interaction with another human agent. Simplifying on these other dimensions, we can extend the experiment to allow for multiple rounds of taking and focus on the question of rationality: Can people think ahead and thus avoid wasteful takings?

There is one unit of a token good. Each player, if not currently in possession of the good, can take it from the other player. Taking is costly, though; the cost of taking is a deadweight loss - a transaction cost (not a transfer from the taker to the dispossessed party). At the end of the experiment, the good is redeemed by the experimenter from whoever possesses the good at this point. Valuations (redemption values) are common knowledge, as is the

3 This claim is not obvious. Thinking ahead may be needed also in a property rule regime, e.g., the price that $B$ is willing to pay for A's asset may depend on the price that B expects to obtain by later selling the asset to $C$. Still, such thinking ahead is less critical for the efficiency of property rules. See Bar-Gill and Persico (2019). 
cost of taking. All treatment variation is between subjects. In all treatments, the computer originally possesses the good. We always have one (human or computer) player who values the good at $100(\mathrm{H})$, and one who values it at $80(\mathrm{~L})$. Each player can use an endowment to "fund" the cost of taking. Any amount not used for taking is for the player to keep. ${ }^{4}$

We run two (related) studies. In study 1 , we keep the following elements constant: the computer is originally endowed with the good; the computer has low valuation; taking costs are symmetric; and each party has an endowment of 40 that can be used to fund takings. Between subjects we manipulate the cost of taking. We set it to 40,20,10 or 5 . With common knowledge of rationality, there should not be any treatment effects. As the taking cost is symmetric, the human player should never take the good, as ultimately the computer would take it back (there could possibly be several rounds of taking and retaking), and both players lose their endowments. This study manipulates the required degree of sophistication: The smaller the taking cost, the more mental steps are needed to find the profit maximizing (initial) choice (since the fixed endowment of 40 allows for more rounds of taking and retaking). Other behavioral forces, beyond the limited ability to think ahead, may also be at play: On the one hand, the experience of seeing the good taken back might alert participants to the fact that taking makes no sense; this would be a learning effect. On the other hand, participants might be tempted to throw good money after bad - a sunk cost effect.

Study 2 is a $2 \times 2$ between subjects design. In one dimension we manipulate whether the human participant or the computer has low valuation. In the second dimension we either fix the cost of taking at 20 for both players, or we set the cost of taking at 40 for the highvaluation player and at 20 for the low-valuation player. With common knowledge of rationality and symmetric taking costs, irrespective of valuations the good stays with the original possessor (the computer player). Taking is futile, as the original possessor would just take the good back. With asymmetric taking costs, the good always ends up with the player who has the lower taking cost (which by design is the low-valuation player). If the computer has lower taking costs, it makes no sense for the human player to take (since the computer would just take back). If the human player has lower taking costs, she should take the good. The computer will not take it back, since then the human player would just retake. We test whether these straightforward theoretical predictions obtain in the experimental setting. ${ }^{5}$ Study 2 is meant to isolate two behavioral effects that might drive the decision to take (or not), so that we can focus on the main variable of interest - rationality or sophistication. First, Study 2 isolates the behavioral motivation to take because your - the human player's - valuation is higher, so that it seems fair or efficient that you get the good. Second, Study 2

$4 \quad$ Players cannot "borrow" against the redemption value of the good to fund takings; this also implies that participants can never lose money in the experiment.

5 The only related experimental study of which we are aware is by one of us with a different coauthor (Engel and Kleine 2015). That experiment studies whether costly innovation is deterred if the innovator must be afraid that bystanders, who have not contributed to the cost of innovation, imitate them. If appropriation is costly, this does not deter investment into innovation, not even if imitation reduces the innovator's profit. The current experiment mainly differs in three respects: (a) the effect of appropriation is more radical: if the token is appropriated, the valuation of the former possessor is zero (unless she decides to take it back); (b) a human participant interacts with the computer, so that social preferences and normative convictions should not play a role; most importantly (c) taking and taking back is possible, so that there is a need for strategic sophistication. 
isolates the effect of symmetry or asymmetry in the parties' taking costs. Symmetry, and even more beneficial asymmetry, might create an impression of entitlement.

Results are even stronger than we had expected when designing the experiment. Even if the cost of taking is so high that participants only have to think a single step ahead to see that taking makes no sense, the large majority of participants take the good. The propensity to make this mistake is significantly lower for more intelligent participants; we measure intelligence using the cognitive reflection test. Interestingly, when asked, after the main experiment, what a participant should have done in the initial round to maximize profit, a large majority gives the correct answer. This suggests that anticipation does not suffice. Many participants seem to need the actual experience of the good being retaken before they fully understand the nature of the game.

Since this experience effect was unexpected, we supplemented the main experiment with four additional treatments (study 3 ). In these treatments, the game has two parts. The first part is identical to one of the treatments in Study 1 . The second part of the experiment is very similar to the first, with only some minor changes (in the parameter values) to make the similarity a bit less obvious. With this design, we give participants a chance to learn from experience. If they took the good in the first part, they see that the computer retakes the good and learn that taking does not pay. We are chiefly interested in the choices that these participants make in the second part. In this part, we manipulate the cost of taking, such that 1,2, 4 or 8 steps of anticipation are needed to see the final outcome. We find a small, weakly significant effect in the expected direction: the more steps are needed, the less participants benefit from experience. Yet the main finding is a strong experience effect: a substantial majority of participants who have taken the good in the first part refrain from taking the good in the second part.

As noted above, we focus on one important type of inefficiency - incurring socially wasteful taking costs. A different type of inefficiency is associated with the misallocation of the good - when the good ends up with the low-valuation party. We defer the full exploration of such allocative inefficiency to future work. And yet our findings about wasteful taking costs raise concerns about allocative inefficiency as well. If the threat of retaking does not deter an initial taking because most people simply cannot think two steps ahead, then the same threat of retaking would not prevent a low-valuation taker from dispossessing a high-valuation owner.

The remainder of the paper is organized as follows: in the next section, we develop hypotheses. Section 3 explains the design of the main experiment. Section 4 reports results from the main experiment. Section 5 reports the design and the results of the supplementary study 3 . Section 6 concludes with discussion. 


\section{Hypotheses}

Rational Choice. As explained in the Introduction, the rational choice prediction is straightforward. It yields the following hypothesis:

\section{Hypothesis 1:}

a) With symmetric taking costs, the human player does not take the good.

b) With asymmetric taking costs, if the computer has lower taking costs, the human player does not take the good.

c) With asymmetric taking costs, if the human player has lower taking costs, she takes the good (and keeps it).

d) It does not matter whether the computer or the human player has high valuation for the good.

Hypotheses 1(a) and 1(b) can be further bolstered by risk aversion; the human player would be concerned that the investment in acquiring the good (by initially taking it) would be lost (by the computer taking it back).

Behavioral Qualifications - Round 1: Limited Sophistication. There is a rich literature on cognitive limitations (see e.g. Frederick 2005, Burks, Carpenter et al. 2009, Chen, Chiu et al. 2012, Deck and Jahedi 2015, Benito-Ostolaza, Hernández et al. 2016, Branas-Garza and Smith 2016, Fehr and Huck 2016). For the purposes of this study, of particular relevance are experiments that show limited foresight (Jehiel 2001), violations of backward induction (Binmore, McCarthy et al. 2002, Johnson, Camerer et al. 2002), a lack of strategic sophistication (Costa-Gomes, Crawford et al. 2001, Carpenter, Graham et al. 2013, Sutter, Czermak et al. 2013, Georganas, Healy et al. 2015, Polonio, Di Guida et al. 2015, Allred, Duffy et al. 2016, Fe and Gill 2018), and limited depth of reasoning (Colman 2003, Kübler and Weizsäcker 2004, Ohtsubo and Rapoport 2006, Strzalecki 2014, Alaoui and Penta 2015, Kneeland 2016), as well as experiments that address strategic complexity (Jones 2014, Muto 2014). These effects have in particular been studied in beauty contest games, as finding the normative solution requires "level k" reasoning, i.e. an infinite regress (Sbriglia 2008, Burnham, Cesarini et al. 2009, Gill and Prowse 2011, Brañas-Garza, Garcia-Munoz et al. 2012, Breitmoser 2012, Luccasen III 2013, Chen, Du et al. 2014, Shapiro, Shi et al. 2014), but also in other contests (Crawford and Iriberri 2007, Bernard 2010, Crawford 2018), the centipede game (McKelvey and Palfrey 1992, Kawagoe and Takizawa 2012), the Colonel Blotto game (Arad and Rubinstein 2012b), sender-receiver games (Kawagoe and Takizawa 2009), guessing games (Nagel 1995), and in the arguably much more accessible 11-20 money request game introduced by Arad and Rubinstein (2012a) (see also Lindner and Sutter 2013).

In our experiment, human participants interact with a computer they know to be maximizing profit. This design feature brackets strategic uncertainty (cf. Agranov and Palfrey 2015). Participants need not generate beliefs about the degree of sophistication of their counterpart. Only their own sophistication is at stake. The lower the taking costs, the human player 
must reason (or anticipate) more steps ahead to realize that taking is pointless. Since thinking more steps ahead is harder, we have the following hypothesis:

Hypothesis 2: When taking costs are lower, the human player is more likely to inefficiently take the good.

Behavioral Qualifications - Round 2: Overoptimism, illusion of control, better than average effect. A series of well-established behavioral effects question Hypothesis 1. Participants interact with a computer they know will maximize profit. This brackets all fairness considerations, and moral inhibition against taking, perceived as stealing. Participants are also not induced to react to actions by their counterparts that they perceive as unfair or immoral. Yet there may be cognitive effects. Participants may be overly optimistic (Van den Steen 2004, Lowe and Ziedonis 2006, Herz, Schunk et al. 2014, Tong, Feiler et al. 2018), they may fall prey to the illusion of control (Langer 1975, Langer and Roth 1975, McKenna 1993, Koehler, Gibbs et al. 1994, Kottemann, Davis et al. 1994, Presson and Benassi 1996) and they may wrongly expect to be "better than average" (the computer included) (Alicke, Klotz et al. 1995, Larrick, Burson et al. 2007, Guenther and Alicke 2010, Brown 2012). Also, if the valuation of the human participant is high, she may be more easily trapped by a seeming efficiency argument, or by falsely equating valuation with strength.

Bias against doing nothing. If the cost of taking is symmetric, the human player maximizes profit by not doing anything. Yet behaviorally it may be difficult not to seize the only option to become active (cf. Tykocinski and Ortmann 2011), also because of an experimenter demand effect (Sawyer 1975, Nichols and Maner 2008, Zizzo 2010, Fleming and Zizzo 2015, De Quidt, Haushofer et al. 2018, Mummolo and Peterson 2018).

The considerations in the previous two paragraphs give us the following behavioral hypothesis (which applies even when taking costs are high and thus there is no need to think many steps ahead):

\section{Hypothesis 3:}

a) Human players take the good also when the taking costs are symmetric.

b) Human players take the good also when taking costs are asymmetric and the computer's taking costs are lower.

c) If the human player has high valuation, she is more likely to take the good.

Behavioral Qualifications - Round 3: Learning from experience and the sunk-cost fallacy. Perfectly rational players immediately understand the game-theoretic solution and play as described in Hypothesis 1. Imperfectly rational players may learn from their interactions with the computer. Specifically, they might make mistakes (in the sense of deviating from the game-theoretic solution) and learn from the computer's reactions to these mistakes (on learning from experience - see, generally, Kolb 2014). It has been shown that experience helps participants overcome limits in strategic thinking (Camerer and Ho 1999, Dufwenberg, Lindqvist et al. 2005, Gneezy, Rustichini et al. 2010), in particular in a beauty contest 
(Schnusenberg and Gallo 2011, Kocher, Sutter et al. 2014). With lower taking cost, players have more opportunities to learn from experience. This is why we expect:

Hypothesis 4: The lower the taking cost, the lower the fraction of the endowment wasted on inefficient takings.

But learning might also work differently. With higher taking cost, the human player may have fewer opportunities to learn, but each opportunity then teaches a more powerful lesson (given the higher cost that is incurred). And with lower taking cost, players may suffer from the sunk cost fallacy - an effect that may counter the learning effect. If a participant has once taken the good from the computer although this will ultimately not maximize her profit, she may be tempted to throw good money after bad (Garland 1990, van Putten, Zeelenberg et al. 2010), and fall prey to the sunk cost fallacy (Arkes and Ayton 1999, Augenblick 2015, Roth, Robbert et al. 2015, Haita-Falah 2017). This gives us the competing hypothesis:

Hypothesis 5: The lower the taking cost, the higher the fraction of the endowment wasted on inefficient takings.

\section{Design}

Setting. We let one human participant interact with a computer. Participants know that the computer is programmed to maximize profit. Each player - the human player and the computer - are endowed with an initial sum. There is one unit of a token good, which is originally possessed by the computer. Each player, if not currently in possession of the good, can take it from the other player. To take, the player must pay a taking cost, funded by the initial endowment. Any amount not used to fund takings is for the player to keep. At the end of the experiment, the good is redeemed by the experimenter from whoever possesses the good (and, practically, only from the human player if she ends up with the good). Endowments, valuations (redemption values) and taking costs are common knowledge.

Study 1 . We fix the value of the good to the human player at 100 , and at 80 to the computer. Taking costs are symmetric. Between subjects we manipulate the taking costs and set them at $40,20,10$ or 5 .

Study 2. The second study is a $2 \times 2$ between subjects design. In one dimension we manipulate valuations. One player values the good at $100(\mathrm{H})$, another at $80(\mathrm{~L})$. We manipulate whether the human player or the computer has the high (or low) valuation. In the second dimension we either fix the taking cost at 20 for both players, or we set the taking costs at 40 for the high-valuation player and at 20 for the low-valuation player.

Table 1 summarizes manipulations and treatments. 


\begin{tabular}{|c|c|c|c|c|c|}
\hline \multicolumn{2}{|c|}{ manipulation } & \multicolumn{2}{c|}{ valuation } & \multicolumn{2}{c|}{ taking cost } \\
\hline study & treatment & human & computer & human & computer \\
\hline \multirow{4}{*}{1} & 10040 & 100 & 80 & 40 & 40 \\
\cline { 2 - 6 } & 10020 & 100 & 80 & 20 & 20 \\
\cline { 2 - 6 } & 10010 & 100 & 80 & 10 & 10 \\
\cline { 2 - 6 } & 1005 & 100 & 80 & 5 & 5 \\
\hline \multirow{4}{*}{2} & $100 a 20$ & 100 & 80 & 20 & 20 \\
\cline { 2 - 6 } & $80 a 20$ & 80 & 100 & 20 & 20 \\
\cline { 2 - 6 } & $100 a$ 40a & 100 & 80 & 40 & 20 \\
\cline { 2 - 6 } & $80 a$ 20a & 80 & 100 & 20 & 40 \\
\hline
\end{tabular}

Table 1

Treatments

Notes: In Study 1, each treatment is represented by a pair of numbers, where the first number is the value of the good to the human player (which is always 100), and the second number is the taking cost $(40,20,10$ or 5$)$. In Study 2, we introduce asymmetry (denoted by the letter "a"), either only with respect to valuations (first and second treatments) or, additionally, with respect to taking cost.

Sophistication. A main goal of our experiment is to evaluate the relationship between player sophistication and efficiency. To see whether a lack of sophistication is critical for treatment effects, we administer, after the main experiment, the cognitive reflection test (Frederick 2005). As concerns have been voiced about habituation (Primi, Morsanyi et al. 2014, Thomson and Oppenheimer 2016), we use the extended version developed by Toplak, West et al. (2014).

Beliefs and Motives. Participants interact with a computer they know will maximize profit. They therefore do not need (descriptive) beliefs to predict the choice that their counterpart will make. But they might use their belief about what most people would do in the situation at hand as a heuristic for making their own choice. This is why, after the main experiment, but before giving participants feedback, we elicit descriptive beliefs. Also, as we have explained in the hypothesis section, the desire to maximize profit is not the only possible motive. To ascertain motives, we elicit, after the main experiment and before providing feedback, participants' normative beliefs, by asking for the choice, in the first round, that would maximize profit.

Further Controls. In the interest of having more scope for explaining results, after the main experiment, we run the 10item version of the Big5 (Rammstedt and John 2007), and ask for demographic information.

Conduct. We have run the experiment in the EconLab of Hamburg University. We had planned to have 30 participants per treatment, but some invited participants did not show up. We effectively had 29 participants in all treatments of study 1 , and 28 participants in all treatments of study 2 , except for the 100 a 40 a treatment, where we only had 24 participants. 130 of 224 participants (58.04\%) were female. All but 5 participants were students, with various majors. The experiment was programmed in zTree (Fischbacher 2007). Participants were invited with hroot (Bock, Baetge et al. 2014). The experiment lasted between 30 and 
45 minutes. Participants on average earned $€ 6.73$ (equivalent to $\$ 7.55$ on the first day of the experiment).

\section{Results}

Choices. Figure 1 summarizes the main result. Visibly, there is only a single treatment $(80 \mathrm{a}$ $20 a$ ) in which the majority of participants made the profit-maximizing choice. This is the treatment in which the cost of taking is asymmetric, and the human participant has lower cost. Hence this is the only treatment where a participant should take in the first round (and there is no second round, because the profit-maximizing computer does not take back). In this treatment, in the first round $71.4 \%$ of all participants make the efficient choice. In all other treatments, this fraction is below $50 \%$ : more than half of all participants waste money by inefficiently taking from the computer.

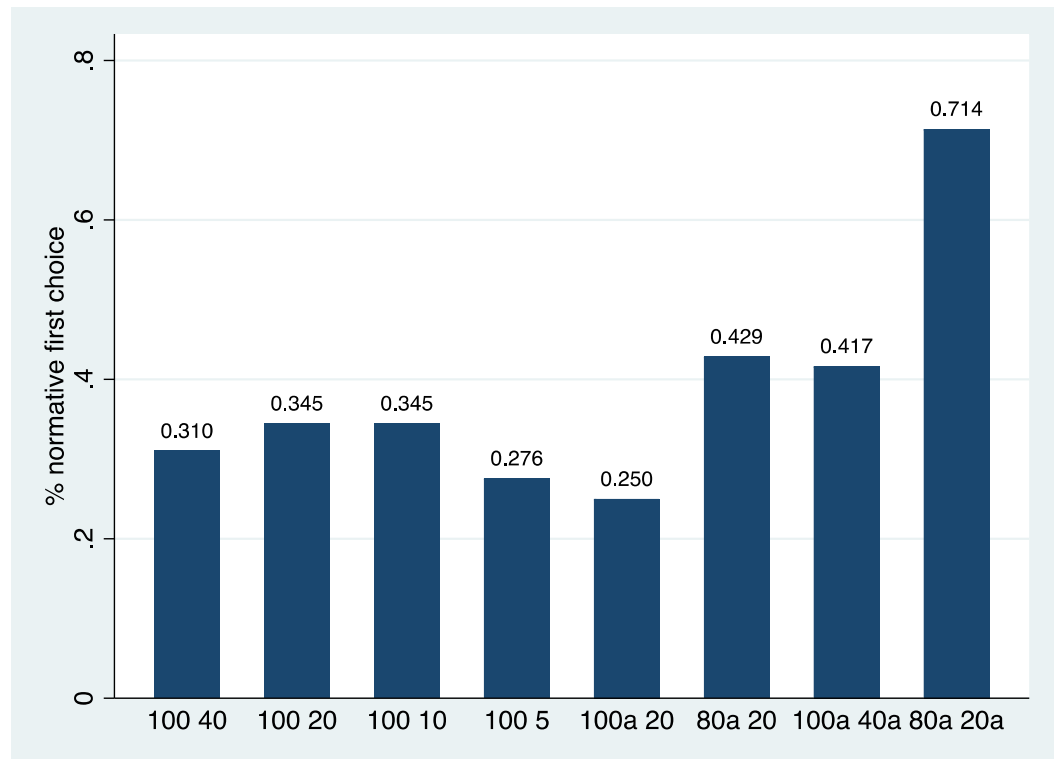

Figure 1

Percentage of Profit Maximizing (First Round) Choices, per Treatment

We now turn to our hypotheses. In $\mathbf{H}_{1 \mathrm{a}}$ we had predicted that human players do not take if the cost of taking is symmetric, i.e. in study 1 and in the 100a 20 and 80a 20 treatments of study 2. We find $69 \%$ taking in the 10040 treatment, $65.5 \%$ in the 10020 and the 10010 treatments, $72.4 \%$ in the 1005 treatment, $75 \%$ in the $100 \mathrm{a} 20$ treatment, and $57.1 \%$ in the 80 a 20 treatment.

We hypothesized that all participants refrain from taking the good in the first round, i.e., not taking is the normative choice. In terms of statistics, we thus have a hypothesis at the limit of the support. A single violation would already refute the hypothesis. We parry the statistical challenge by a series of binomial tests of the auxiliary hypothesis that the fraction of normative choices is bigger than $10 \%, 20 \% \ldots 90 \%$. Given our sample size, in a one-sided 
test at $a=5 \%$, we can exclude that the fraction of normative choices is bigger than $60 \%$ in the 10040 and 10020 treatments (each $\mathrm{N}=29, \mathrm{p}=.007$ ), bigger than $50 \%$ in the 10010 treatment $(\mathrm{N}=29, \mathrm{p}=.024)$ and in the 1005 treatment $(\mathrm{N}=29, \mathrm{p}=.013)$, bigger than $70 \%$ in the 100a 20 treatment $(\mathrm{N}=28, \mathrm{p}=.003)$ and in the 80a 20 treatment $(\mathrm{N}=28, \mathrm{p}=.006)$. If we pool the data over all 6 treatments with symmetric taking cost, we can exclude that the fraction of profit maximizing choices is above $50 \%(\mathrm{~N}=172, \mathrm{p}=.000006)$. We thus have support for the competing $\mathrm{H}_{3 \mathrm{a}}$ and conclude

Result 1: When the cost of taking is symmetric, the majority of participants take the good in the first round.

In $\mathbf{H}_{1 \mathrm{~b}}$ we had predicted that participants would not take if the computer has lower cost, i.e. in treatment $100 \mathrm{a} 40 \mathrm{a}$. Actually $58.3 \%$ do take. Given the rather small size of this sample, statistically we can only exclude that the rate of normative choices is $80 \%$ or higher $(N=24$, $\mathrm{p}=.00004)$. We thus have support for the competing $\mathbf{H}_{3 \mathrm{~b}}$ and conclude

Result 2: A substantial minority of participants take the good in the first round even when the computer's cost of taking is lower.

$\mathbf{H}_{1 \mathrm{c}}$ looks at the opposite situation, where the human player has lower taking cost than the computer, i.e. at the 80 a 20 a treatment. Descriptively in this treatment $71.4 \%$ maximize profit by taking the good in the first round. Statistically we can exclude that this fraction is below $50 \%(N=28, p=.018)$. We conclude

Result 3: The majority of participants take the good in the first round when the computer's cost of taking is higher.

In $\mathbf{H}_{1 \mathrm{~d}}$ we had expected that the rate of normative choices would be the same regardless of who has higher valuation - the human player of the computer, i.e. that there is no difference between treatments 100a 20 and 80a 20. Indeed, we cannot reject the null hypothesis that choices are identical (regressing normative choice on treatment, $N=56, p=.164$ ). This rejects $\mathbf{H}_{3 \mathbf{c}}$.

$\mathbf{H}_{2}$ is motivated by a possible lack of sophistication. We had expected fewer efficient choices when the participant had to think more steps ahead. Hence taking in the first round should have been most frequent in the 1005 treatment (at most 8 steps), less so in the 100 10 treatment (at most 4 steps), even less in the 10020 treatment (at most 2 steps), and least in the 10040 treatment (at most 1 step). Figure 1 shows that this is not what we find. Descriptively, the take rate is indeed highest in the 1005 treatment, but it is lowest in the 10020 and 10010 treatments. Statistically we do not find any treatment differences.

$\mathbf{H}_{4}$ and $\mathbf{H}_{5}$ make competing predictions, based on a beneficial effect of learning from experience vs. a detrimental effect from the sunk cost fallacy. As Figure 2 shows, we do not have a perfectly clear picture. In the 100a 20 treatment, choices strongly improve from the first to the second round. In the second round, little more than $20 \%$ of all participants take the good, while more than $70 \%$ had in the first round. In the 10020 treatment, there is also 
a positive development, but it is less pronounced. In the 80 a 20 treatment, choices in both rounds are almost identical. Yet in the two treatments that make room for longer sequences $(100$ 10, 100 5) overall curves slope down: taking becomes even more prevalent over time.

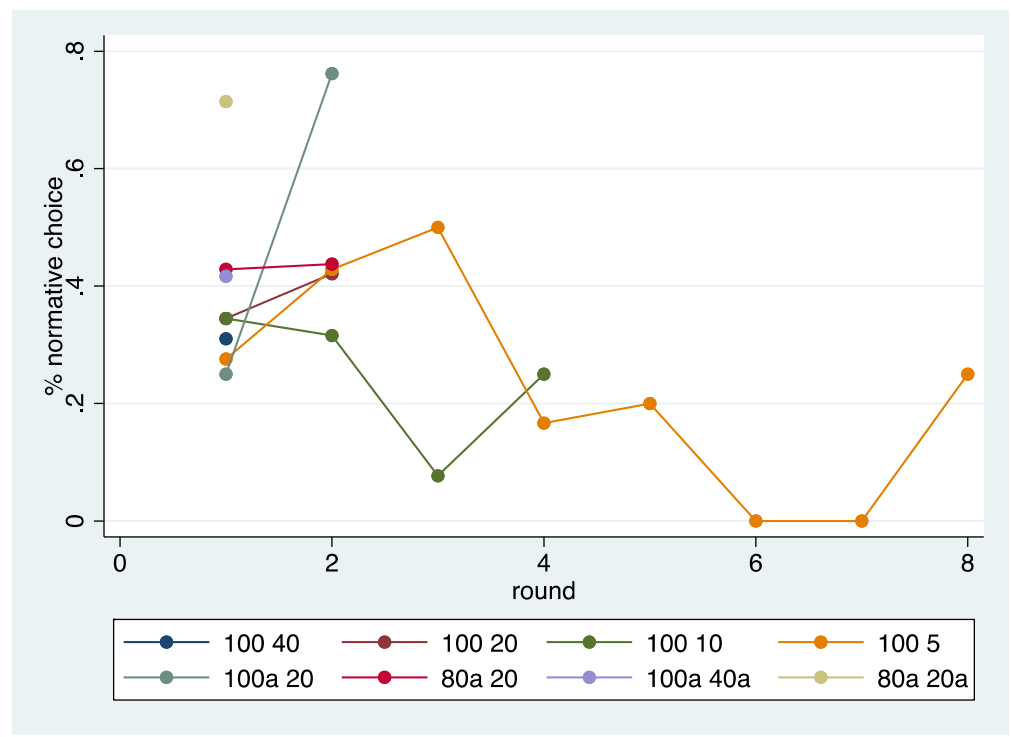

Figure 2

Normative Choices over Time

We predicted that sophistication would be correlated with efficiency. We did not find that normative choices are less frequent when greater sophistication is required to discern the normative choice (i.e., when participants had to think more steps ahead). Still we found that sophistication matters. In Model 1 of Table $2,{ }^{6}$ we regress whether the participant has made the normative choice (to take the good in treatment 80a 20a, and to not take it in the remaining treatments) on treatment and the participant's CRT score - the number of logic problems, out of seven, that the participant solved correctly. As the regression shows, the better a participant is at solving these problems, the more likely she is to make the normative choice in the main experiment. A participant who answered all seven CRT problems correctly was $7 * 5.3=37.1 \%$ more likely to make the normative choice, as compared to a participant who did not answer any of the questions correctly. We conclude

Result 4: The better a participant performs in the cognitive reflection test, the more likely she is to maximize profit in the main experiment.

6 In the interest of facilitating the interpretation, we estimate linear probability models. Hence coefficients capture the marginal probability of being in one of the treatments, or of a one unit change in the remaining regressors. 


\begin{tabular}{|l|l|l|l|l|}
\hline & model 1 & model 2 & model 3 & model 4 \\
\hline & & & & \\
\hline 10020 & .047 & .072 & .066 & .036 \\
& $(.122)$ & $(.114)$ & $(.114)$ & $(.122)$ \\
\hline 10010 & .071 & .121 & .106 & .099 \\
& $(.123)$ & $(.115)$ & $(.116)$ & $(.124)$ \\
\hline 1005 & -.005 & .055 & .052 & .029 \\
& $(.123)$ & $(.115)$ & $(.115)$ & $(.122)$ \\
\hline $100 a$ 20 & -.029 & .005 & .019 & -.009 \\
& $(.124)$ & $(.116)$ & $(.116)$ & $(.125)$ \\
\hline $80 a$ 20 & .099 & .158 & .159 & .143 \\
& $(.124)$ & $(.116)$ & $(.116)$ & $(.122)$ \\
\hline $100 a$ 40a & .100 & $-.329^{\star}$ & $-.341^{\star}$ & $-.348^{\star}$ \\
& $(.129)$ & $(.141)$ & $(.142)$ & $(.147)$ \\
\hline $80 a$ 20a & $.445^{\star \star \star}$ & .139 & .137 & .140 \\
& $(.124)$ & $(.127)$ & $(.127)$ & $(.133)$ \\
\hline CRT & $.053^{\star \star}$ & $.033^{\star}$ & $.036^{\star}$ & $.036^{\star}$ \\
& $(.017)$ & $(.016)$ & $(.016)$ & $(.017)$ \\
\hline descriptive belief & & $.788^{\star \star \star}$ & $.799^{\star \star \star}$ & $.785^{\star \star \star}$ \\
& & $(.137)$ & $(.137)$ & $(.143)$ \\
\hline normative belief & & & -.071 & -.069 \\
& & & $(.071)$ & $(.074)$ \\
\hline cons & .080 & -.174 & -.134 & .175 \\
& $(.114)$ & $(.115)$ & $(.121)$ & $(.383)$ \\
\hline demographic controls & $\mathrm{NO}$ & $\mathrm{NO}$ & $\mathrm{NO}$ & YES \\
\hline $\mathrm{N}$ & 224 & 224 & 224 & 224 \\
\hline
\end{tabular}

Table 2

Regressions

OLS

dv: normative choice

reference category: 10040

CRT: \# of 7 tasks with normative solution; descriptive belief: \% of session; normative belief: dummy that is 1 if participant correctly defines normative choice in first round; demographic controls: gender, age, student status, work experience (dummy), econ student (dummy), Big5 scores. Standard errors in parenthesis. ${ }^{\star \star \star} p<.001,{ }^{\star \star} p<.01,{ }^{*} p<.05,{ }^{+} p<.1$

Taken together, these results suggest that whether participants make the normative choice is a matter of intelligence. But the majority is not intelligent enough to discern the normative choice, even if the game will be over in the next round. Thinking ahead a single step is already too much.

Beliefs and Motives. After the main experiment, we elicit beliefs. Descriptive beliefs, i.e., the participant's estimate about the fraction of her session that have made the normative choice, have high explanatory power (Models 2-4 in Table 2). Two explanations (that are not mutually exclusive) are possible: (1) Participants believe that others are like them; and (2) Participants' choice is influenced by what they believe others would do. 
With one exception, ${ }^{7}$ in all treatments more than $60 \%$ of participants correctly indicate the normative choice when explicitly asked for it (normative beliefs). But these normative beliefs are not significantly correlated with actual choices (Model 3 in Table 2). Did participants understand the game, but refrain from maximizing profit? They knew they were interacting with a computer programmed to maximize profit. This makes it very unlikely that motivational effects, like social preferences, explain choices.

A closer look at the design of the experiment offers a more convincing interpretation. We withheld feedback until the very end of the experiment, but participants experienced the computer's reaction if they took the good in the initial round. If the cost of taking was low enough, they also experienced the computer's reaction when they took the good back. Hence when asked for the normative choice, participants had the benefit of hindsight. This experience helped many participants to identify the normative choice. Pooled over all treatments, normative beliefs are significantly more likely to be correct than first round choices (ttest, $\mathrm{N}=224, \mathrm{p}<.001)$. For most treatments, this also holds if we split the analysis by treatment: $10040(\mathrm{~N}=29, \mathrm{p}<.001) ; 10020(\mathrm{~N}=29, \mathrm{p}=.0078) ; 1005(\mathrm{~N}=29, \mathrm{p}=.0003)$; 100a $20(\mathrm{~N}=28, \mathrm{p}<.001)$; 80a $20(\mathrm{~N}=28, \mathrm{p}=.0013)$; 100a 40a $(\mathrm{N}=24, \mathrm{p}=.008)$. The difference is only weakly significant for the 10010 teatment $(N=29, p=.0805)$. And it is insignificant for the $80 \mathrm{a} 20 \mathrm{a}$ treatment. This is the treatment in which participants maximize profit by taking the good in the first round.

We conclude

Result 5: If maximizing profit requires that participants refrain from taking the good, they must have experienced that taking does not pay to understand the incentive structure.

Model 4 shows that this finding is robust to adding Big5 scores and demographic information as controls.

\section{The Benefit of Experience}

The design of the main experiment reflects our behavioural theory. In Hypothesis 4 and the literature motivating it, we had considered that experience matters. But we had expected it to already matter within a game of multiple rounds. This has not been the case. The mere fact that the computer retakes does not seem to teach participants a lesson. Yet when asked, after the main experiment is finished, which choice would have maximized profit, many more participants get it right. This suggests that experience only helps if the participant has indeed lost the good, and his endowment. While this explanation is strongly suggested by the results of the main experiment, it was not part of our theory. As it is an ex post rationalization of the data, we sought to confirm the role of experience by running study 3 , with four additional treatments. 
In all of these treatments, the first part replicates the 10020 treatment in the main experiment: Participants interact with a computer they know to be programmed for profit maximization. The computer values the good at 80 , the human participant at 100 . The symmetric cost of taking is 20 . The symmetric endowment for taking is 40 . The good is initially allocated to the computer. As the endowment and the cost of taking are symmetric, participants have no chance to keep the good. Yet to see this, they have to correctly anticipate two rounds of taking. When choosing in the first part of the experiment, participants only know that the experiment has further parts, not what these parts are about.

Now we add a second part. In this second part, participants again interact with a computer programmed to maximize profit. They play a game with the same structure. To make the structural similarity a little less obvious, we multiply all parameters by 2 . The cost of taking is either $80,40,20$ or 10 . Hence participants need 1, 2, 4 or 8 rounds of anticipation to see that taking is pointless. Participants receive choice-based compensation for both parts of the experiment. ${ }^{8}$

Table 3 summarizes the four treatments.

\begin{tabular}{|c|c|c|c|c|c|c|c|c|c|c|c|}
\hline & \multicolumn{5}{|c|}{ first round } & \multicolumn{5}{|c|}{ second round } \\
\hline & & \multicolumn{2}{|c|}{ valuation } & \multicolumn{2}{|c|}{ taking cost } & \multirow{2}{*}{$\begin{array}{c}\text { taking en- } \\
\text { dowment } \\
\text { both }\end{array}$} & \multicolumn{2}{|c|}{ valuation } & \multicolumn{2}{|c|}{ taking cost } & $\begin{array}{l}\text { taking en- } \\
\text { dowment }\end{array}$ \\
\hline study & $\begin{array}{l}\text { treat- } \\
\text { ment }\end{array}$ & $\begin{array}{l}\text { hu- } \\
\text { man }\end{array}$ & $\begin{array}{l}\text { com- } \\
\text { puter }\end{array}$ & $\begin{array}{c}\text { hu- } \\
\text { man }\end{array}$ & $\begin{array}{l}\text { com- } \\
\text { puter }\end{array}$ & & $\begin{array}{c}\text { hu- } \\
\text { man }\end{array}$ & $\begin{array}{l}\text { com- } \\
\text { puter }\end{array}$ & $\begin{array}{l}\text { hu- } \\
\text { man }\end{array}$ & $\begin{array}{l}\text { com- } \\
\text { puter }\end{array}$ & both \\
\hline \multirow{4}{*}{3} & 2080 & 100 & 80 & 20 & 20 & 40 & 200 & 160 & 80 & 80 & 80 \\
\hline & 2040 & 100 & 80 & 20 & 20 & 40 & 200 & 160 & 40 & 40 & 80 \\
\hline & 2020 & 100 & 80 & 20 & 20 & 40 & 200 & 160 & 20 & 20 & 80 \\
\hline & 2010 & 100 & 80 & 20 & 20 & 40 & 200 & 160 & 10 & 10 & 80 \\
\hline
\end{tabular}

Table 3

\section{Treatments of Study 3}

We have run these supplementary treatments in the same lab, using the same software for inviting participants and for running the experiment. We had 117 participants from the same subject pool (27 in the 2040 condition, and 30 in the remaining conditions). Participants on average earned $10.38 €$ in the 2080 condition, $12.39 €$ in the 2040 condition, $13.23 €$ in the 2020 condition, and $13.67 €$ in the 2010 condition.

As Figure 4 shows, we find pronounced experience effects. The effect is biggest in the 20 40 treatment, where the fraction of participants who refrain from taking the good in the first round jumps from less than $30 \%$ without experience to more than $75 \%$ with experience (Wilcoxon, $N=27, p=.0044$, two-sided). We also find a strong experience effect in the 2020 condition, where the fraction of normative choices increases from more than $45 \%$ to more than $75 \%$ (Wilcoxon, $N=30, p=.0352$ ). It is a bit smaller in the 2080 case $(37 \%$ versus $60 \%$,

8 We accept the resulting possibility of hedging as we want to make sure that (a) participants truly feel the experience from the first part and (b) have a strong incentive to take the second part seriously. Note that this design gives us an upper bound of the experience effect. From study 1 we expect that many participants earn little or nothing in the first part. Therefore, they have a strong incentive to get it right in the second part. 
n.s.), and least pronounced in the 2010 condition (50\% versus $60 \%$, n.s.). Overall, the experience effect is clearly significant $(\mathrm{N}=117, \mathrm{p}=.0001){ }^{9}$

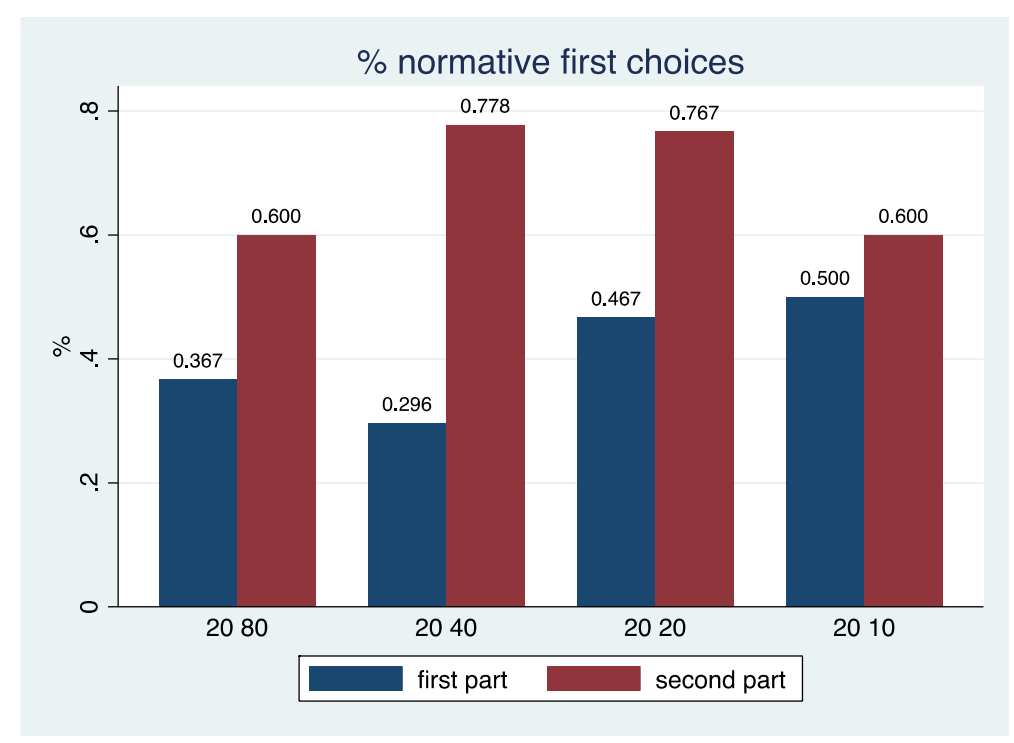

Figure 3

Study 3 Results

We conclude -

Result 6: When participants have had a chance to experience, in an analogous situation, that taking is pointless, they are less likely to take the good in the first round.

While experience matters, the magnitude of this effect does not vary in a systematic way across treatments. ${ }^{10}$ Taken together, our findings from the main experiment and the supplementary treatments show that the key challenge for efficiency is not the need to anticipate multiple rounds of taking. The main deficiency is the need to engage in anticipation, however simple. This deficiency is at least partly cured by bad experiences in a closely similar situation. Yet even then, the degree of inefficient taking remains pronounced.

\section{Conclusion}

The normative concern is even stronger than we had expected. For the large majority of participants, it is too much to anticipate even a single step. They take the good even if it would only have required a moment of reflection to see that the computer will immediately

9 Despite the fact that the first part of the experiment is identical for all four supplementary treatments, descriptively the fraction of participants taking the good in the first round differs across these treatments (Figure 4). Yet these differences do not reach statistical significance. We also do not find a difference between choices in the first part of the supplementary treatments and choices in the (identical) 10020 condition. Regressions showing these non-effects are available from the authors upon request.

10 We only find a weakly significant negative effect $(p=.055)$, if we regress the fact that a participant has made the normative choice in the second part but not in the first part on treatment as a continuous variable. This additional regression is available from the authors upon request. 
take it back, and that they will not have the means to retake it. The only intervention that helps is experience.

In the interest of isolating the cognitive effect, we have given participants perfect information about the preferences of their counterpart, and we have ruled out any motivational concerns. In the field, all these complications would be present. They might make it even harder to achieve efficiency.

With our data, we have found a strong cognitive impediment to efficiency. Yet we cannot say whether participants have simply not been intelligent enough to see the normative choice, or whether they have fallen prey to one of the cognitive illusions discussed in the hypothesis section: participants might have been overly optimistic, they might have fallen prey to the illusion of control, they might have wrongly expected to be "better than average", or they may have found it hard not to do anything. ${ }^{11}$ We leave discriminating between these cognitive effects to future work.

The only reasonably effective remedy seems to be experience. This is good news and bad. In a world without (absolute) property rights, there would still be a way to achieve a higher degree of efficiency. Yet this intervention is costly. Individuals must first have lost money in a futile attempt at seizing an asset. Worse even: those from whom they take stand to lose a comparable amount, with no compensation for the transaction cost. And, since in the real world the second taking opportunity will not be identical to the first (unlike in the artificial lab environment), the learning effect may be even smaller than the one that we measured.

We radically simplified the setting and studied a world with only two agents. And even in this simple world, we find rampant inefficiency. In the real world, with many potential takers, the cognitive requirements would be even more demanding and we would expect even more wasteful taking.

Consequently, we have a clear normative message: in a counterfactual world where property rights are weakly protected - by a liability rule or by an underenforced property rule inefficiency is to be expected, as individuals will take a good even if it is very likely that they will not be able to keep it. To achieve efficient outcomes when property rights are weakly protected, we need a degree of sophistication that most people do not have. Strong property rights do not require such sophistication. Adequately enforced property rules should be preferred, because they are dummy proof.

11 Note though that doing nothing would also be the efficient choice in almost all situations of a hypothetical world with no or weak property rights. 


\section{References}

Agranov, Marina AND Thomas R Palfrey (2015). "Equilibrium Tax Rates and Income Redistribution: A Laboratory Study." Journal of Public Economics 130: 45-58.

Alaoul, LaRbi And Antonio Penta (2015). "Endogenous Depth of Reasoning." The Review of Economic Studies 83(4): 1297-1333.

Alicke, Mark D, Mary L KlotZ, David L BReitenbecher, Tricia J YuRak and DebBie S VRedenBURG (1995). "Personal Contact, Individuation, and the Better-than-average Effect." Journal of Personality and Social Psychology 68(5): 804-825.

AlLRED, SARAH, SeAn DufFy AND JoHn SMith (2016). "Cognitive Load and Strategic Sophistication." Journal of Economic Behavior \& Organization 125: 162-178.

Arad, Ayala and Ariel Rubinstein (2012a). "The 11-20 Money Request Game. A Level-k Reasoning Study." American Economic Review 102(7): 3561-3573.

ARAD, AyAla AND ARIEL Rubinstein (2012b). "Multi-dimensional Iterative Reasoning in Action. The Case of the Colonel Blotto Game." Journal of Economic Behavior \& Organization 84(2): 571-585.

ARKes, Hal R And Peter Ayton (1999). "The Sunk Cost and Concorde Effects. Are Humans Less Rational than Lower Animals?" Psychological Bulletin 125(5): 591-600.

Augenblick, Ned (2015). "The Sunk-cost Fallacy in Penny Auctions." Review of Economic Studies 83(1): 58-86.

AYRES, IAN (2005). Optional Law. The Structure of Legal Entitlements, University of Chicago Press.

BAR-GILL, OREn AND LuCIAN ARYe Bebchuk (2010). "Consent and Exchange." Journal of Legal Studies 39(2): 375-397.

BAR-GILL, OREn AND ChRISTOPH Engel (2016). "Bargaining in the Absence of Property Rights. An Experiment." Journal of Law and Economics 59(2): 477-495.

Bar-Gill, Oren And Christoph Engel (2018). "How to Protect Entitlements. An Experiment." Journal of Law and Economics 61(3): 525-553.

Bar-Gill, Oren and Nicola Persico (2016). "Exchange Efficiency with Weak Ownership

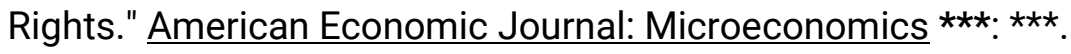

BAR-GILL, OREN AND Nicola Persico (2019). "Bounded Rationality and the Theory of Property." Notre Dame Law Review ***: ***. 
BEBCHUK, LUCIAN ARYE (2001). "Property Rights and Liability Rules. The ex ante View of the Cathedral." Michigan Law Review 100: 601-639.

Benito-Ostolaza, JuAn M, PenÉlope HeRnández and JuAn A SANCHIS-LloPis (2016). "Do Individuals with Higher Cognitive Ability Play More Strategically?" Journal of Behavioral and Experimental Economics 64: 5-11.

BernARD, MARK (2010). "Level-k Reasoning in Contests." Economics Letters 108(2): 149152.

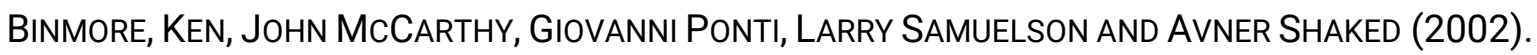
"A Backward Induction Experiment." Journal of Economic Theory 104(1): 48-88.

BOCK, OLAF, INGMAR BAETGE AND ANDREAS NICKLISCH (2014). "hroot: Hamburg Registration and Organization Online Tool." European Economic Review 71: 117-120.

Bosch-Domenech, Antoni, Jose g Montalvo, Rosemarie Nagel and Albert Satorra (2002). "One, Two, (Three), Infinity, ...: Newspaper and Lab Beauty-contest Experiments." American Economic Review 92(5): 1687-1701.

Brañas-Garza, Pablo, Teresa Garcia-Munoz and Roberto Hernán GonZÁlez (2012). "Cognitive Effort in the Beauty Contest Game." Journal of Economic Behavior \& Organization 83(2): 254-260.

Branas-Garza, Pablo and John Smith (2016). "Cognitive Abilities and Economic Behavior." Journal of Economic Behavior \& Organization 64: 1-4.

BREITMOSER, YVES (2012). "Strategic Reasoning in p-beauty Contests." Games and Economic Behavior 75(2): 555-569.

BROWN, JONATHON D (2012). "Understanding the Better than Average Effect. Motives (Still) Matter." Personality and Social Psychology Bulletin 38(2): 209-219.

BuRks, Stephen V, JefFrey P CARPENTER, LoRenz Goette And Aldo Rustichini (2009). "Cognitive Skills Affect Economic Preferences, Strategic Behavior, and Job Attachment." Proceedings of the National Academy of Sciences 106(19): 7745-7750.

Burnham, Terence C, David Cesarini, Magnus Johannesson, Paul Lichtenstein and BJörn WALLACE (2009). "Higher Cognitive Ability is Associated with Lower Entries in a pbeauty Contest." Journal of Economic Behavior \& Organization 72(1): 171-175.

Calabresi, Guido and A. Douglas Melamed (1972). "Property Rules, Liability Rules and Inalienability. One View of the Cathedral." Harvard Law Review 85: 1089-1128.

CAmerer, Colin F. AND TeCK HuA Ho (1999). "Experience-Weighted Attraction Learning in Normal Form Games." Econometrica 67(4): 827-874. 
Carpenter, Jeffrey, Michael Graham and Jesse Wolf (2013). "Cognitive Ability and Strategic Sophistication." Games and Economic Behavior 80: 115-130.

Chen, ChIA-ChIng, I-Ming ChIU, John Smith AND TetsuiJ YAMAdA (2012). Too Smart to Be Selfish? Measures of Cognitive Ability, Social Preferences, and Consistency. http://mpra.ub.uni-muenchen.de/41078/.

Chen, Shu-Heng, Ye-Rong Du And Lee-Xieng Yang (2014). "Cognitive Capacity and Cognitive Hierarchy. A Study Based on Beauty Contest Experiments." Journal of Economic Interaction and Coordination 9(1): 69-105.

COLMAN, ANDREW M (2003). "Depth of Strategic Reasoning in Games." Trends in Cognitive Sciences 7(1): 2-4.

Costa-Gomes, Miguel, Vincent P Crawford and Bruno Broseta (2001). "Cognition and Behavior in Normal-form Games. An Experimental Study." Econometrica 69(5): 11931235.

CRAWFORD, VINCENT P (2018). "'Fatal Attraction" and Level-k thinking in Games with Nonneutral Frames." Journal of Economic Behavior \& Organization 156: 219-224.

Crawford, Vincent P AND NAgore IRIBerRI (2007). "Level-k Auctions. Can a Nonequilibrium Model of Strategic Thinking Explain the Winner's Curse and Overbidding in Privatevalue Auctions?" Econometrica 75(6): 1721-1770.

De QuidT, JonAthan, Johannes Haushofer AND Christopher Roth (2018). "Measuring and Bounding Experimenter Demand." American Economic Review 108(11): 32663302.

Deck, CARY AND SALAR JAHEdi (2015). "The Effect of Cognitive Load on Economic Decision Making. A Survey and New Experiments." European Economic Review 78: 97-119.

DufWEnberg, Martin, Tobias Lindqvist and Evan Moore (2005). "Bubbles and Experience. An Experiment." American Economic Review 95(5): 1731-1737.

Engel, Christoph And MARco KLeINe (2015). "Who is Afraid of Pirates? An Experiment on the Deterrence of Innovation by Imitation." Research Policy 44: 20-33.

FE, EdUARDO AND DAVID GILL (2018). Cognitive skills and the development of strategic sophistication.

https://krannert.purdue.edu/programs/phd/working-papers-series/2018/ 1310_Gill_cognitive.pdf.

FeHR, Dietmar And StefFen Huck (2016). "Who Knows it is a Game? On Strategic Awareness and Cognitive Ability." Experimental Economics 19(4): 713-726.

FISCHBACHER, URS (2007). "z-Tree. Zurich Toolbox for Ready-made Economic Experiments." Experimental Economics 10: 171-178. 
Fleming, Piers ANd Daniel John Zizzo (2015). "A Simple Stress Test of Experimenter Demand Effects." Theory and Decision 78(2): 219-231.

FREDERICK, SHANE (2005). "Cognitive Reflection and Decision Making." Journal of Economic Perspectives 19: 25-42.

GARLAND, HowARD (1990). "Throwing Good Money After Bad. The Effect of Sunk Costs on the Decision to Escalate Commitment to an Ongoing Project." Journal of Applied Psychology 75(6): 728-731.

Georganas, Sotiris, Paul J Healy and Roberto A Weber (2015). "On the Persistence of Strategic Sophistication." Journal of Economic Theory 159: 369-400.

GILL, DAVID AND VICTORIA ProwSE (2011). A Novel Computerized Real Effort Task Based on Sliders. http://ssrn.com/abstract=1732324.

GNeEZY, URI, Aldo Rustichini ANd AleXANDER Vostroknutov (2010). "Experience and Insight in the Race Game." Journal of Economic Behavior \& Organization 75(2): 144-155.

GUENTHER, COREY L AND MARK D AliCKE (2010). "Deconstructing the Better-than-average Effect." Journal of Personality and Social Psychology 99(5): 755-770.

HAITA-FALAH, CORINA (2017). "Sunk-cost Fallacy and Cognitive Ability in Individual Decisionmaking." Journal of Economic Psychology 58: 44-59.

Herz, Holger, Daniel Schunk And Christian Zehnder (2014). "How do Judgmental Overconfidence and Overoptimism Shape Innovative Activity?" Games and Economic Behavior 83: 1-23.

JeHIEL, PHILIPPE (2001). "Limited Foresight May Force Cooperation." Review of Economic Studies 68(2): 369-391.

Johnson, ERIC J, Colin CAMERER, SANKAR SEn AND TALIA RYMon (2002). "Detecting Failures of Backward Induction. Monitoring Information Search in Sequential Bargaining." Journal of Economic Theory 104(1): 16-47.

Jones, MATTHEW T (2014). "Strategic Complexity and Cooperation. An Experimental Study." Journal of Economic Behavior \& Organization 106: 352-366.

Kaplow, Louis And SteVen Shavell (1996). "Property Rules versus Liability Rules. An Economic Analysis." Harvard Law Review 109: 713-790.

KAWAgOE, TOSHIJI AND HIROKAZU TAKIZAWA (2009). "Equilibrium Refinement vs. Level-k analysis. An Experimental Study of Cheap-talk Games with Private Information." Games and Economic Behavior 66(1): 238-255.

KaWAgoe, ToshiJI AND HiRokAZU TakizaWA (2012). "Level-k Analysis of Experimental Centipede Games." Journal of Economic Behavior \& Organization 82(2-3): 548-566. 
KNEELAND, TERRI (2016). "Coordination under Limited Depth of Reasoning." Games and Economic Behavior 96: 49-64.

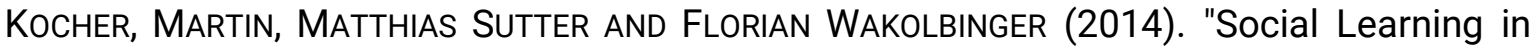
Beauty-Contest Games." Southern Economic Journal 80(3): 586-613.

KoEHLER, JoNATHAN J, BRIAN J GIBBS AND RoBin M HOGARTH (1994). "Shattering the Illusion of Control. Multi-shot versus Single-shot Gambles." Journal of Behavioral Decision Making 7(3): 183-191.

KOLB, DAVID A (2014). Experiential Learning. Experience as the Source of Learning and Development, FT press.

Kottemann, Jeffrey E, Fred D Davis And William E Remus (1994). "Computer-assisted Decision Making. Performance, Beliefs, and the Illusion of Control." Organizational Behavior and Human Decision Processes 57(1): 26-37.

KÜBLER, DOROTHEA AND GEORg WeIZSÄCKER (2004). "Limited Depth of Reasoning and Failure of Cascade Formation in the Laboratory." Review of Economic Studies 71: 425441.

LANGeR, ElLEN J (1975). "The Illusion of Control." Journal of Personality and Social Psychology 32(2): 311-328.

LANGER, Ellen J AND JANE Roth (1975). "Heads I Win, Tails it's Chance. The Illusion of Control as a Function of the Sequence of Outcomes in a Purely Chance Task." Journal of Personality and Social Psychology 32(6): 951-955.

LARRICK, Richard P, KATHERINe A BuRSON AND JACK B Soll (2007). "Social Comparison and Confidence. When Thinking you're Better than Average Predicts Overconfidence (and When it Does not)." Organizational Behavior and Human Decision Processes 102(1): 76-94.

LINDNER, FLORIAN AND MATTHIAS SUTTER (2013). "Level-k Reasoning and Time pressure in the 11-20 Money Request Game." Economics Letters 120(3): 542-545.

LOWE, Robert A AND ARVIDS A ZIEDONIS (2006). "Overoptimism and the Performance of Entrepreneurial Firms." Management Science 52(2): 173-186.

LUCCASEN III, R ANDREW (2013). "Does Context Promote Higher-level Thinking in the Beauty Contest?" Economics Letters 121(3): 421-424.

MCKelVeY, Richard D AND Thomas R PALFREY (1992). "An Experimental Study of the Centipede Game." Econometrica 60: 803-836.

McKenna, Frank P (1993). "It Won't Happen to Me. Unrealistic Optimism or Illusion of Control?" British Journal of Psychology 84(1): 39-50. 
Mummolo, Jonathan ANd ERIK Peterson (2018). "Demand Effects in Survey Experiments. An Empirical Assessment." American Political Science Review: 1-13.

Muto, Nozomu (2014). "Strategic Complexity in Repeated Extensive Games." Games and Economic Behavior 83: 45-52.

NAGEL, Rosemarie (1995). "Unraveling in Guessing Games: An Experimental Study." American Economic Review 85(5): 1313-1326.

NiCHOLS, AUSTIN LeE AND JON K MANER (2008). "The Good-subject effect. Investigating Participant Demand Characteristics." Journal of General Psychology 135(2): 151-166.

OHTSUBO, YohsUKE AND AMNON RAPOPORT (2006). "Depth of Reasoning in Strategic Form Games." The Journal of Socio-Economics 35(1): 31-47.

Polonio, LUCA, SibILLA DI GUIDA AND GIORgIO CoRICELLI (2015). "Strategic Sophistication and Attention in Games. An Eye-tracking Study." Games and Economic Behavior 94: 8096.

Presson, Paul K and Victor A Benassi (1996). "Illusion of Control. A Meta-analytic Review." Journal of Social Behavior and Personality 11(3): 493-511.

Primi, Caterina, KInga MorsanyI ANd Francesca Chiesi (2014). Measuring the basics of probabilistic reasoning: The IRT-based construction of the probabilistic reasoning questionnaire. Sustainability in statistics education. Proceedings of the Ninth International Conference on Teaching Statistics (ICOTS9.

Rammstedt, Beatrice and Oliver P. John (2007). "Measuring Personality in One Minute or Less. A 10-item Short Version of the Big Five Inventory in English and German." Journal of Research in Personality 41: 203-212.

Roth, Stefan, Thomas Robbert and LenNart Straus (2015). "On the Sunk-cost Effect in Economic Decision-making. A Meta-Analytic Review." Business Research 8(1): 99-138.

SAWYeR, AlAN G (1975). "Demand Artifacts in Laboratory Experiments in Consumer Research." Journal of Consumer Research 1(4): 20-30.

SbrigliA, PATRIZIA (2008). "Revealing the Depth of Reasoning in p-beauty Contest Games." Experimental Economics 11(2): 107-121.

SCHNUSENBERG, OliVer AND ANDRÉs Gallo (2011). "On Cognitive Ability and Learning in a Beauty Contest." Journal for Economic Educators 11(1): 13-24.

ShAPIRO, DMITRY, XIANWEN SHI AND ARTIE ZILLANTE (2014). "Level-k Reasoning in a Generalized Beauty Contest." Games and Economic Behavior 86: 308-329.

Stahl, Dale O. ANd PaUl Wilson (1995). "On Players Models of Other Players. Theory and Experimental Evidence." Games and Economic Behavior 10(1): 218-254. 
StRZALECKI, TomASz (2014). "Depth of Reasoning and Higher Order Beliefs." Journal of Economic Behavior \& Organization 108: 108-122.

Sutter, Matthias, Simon Czermak And Francesco FerI (2013). "Strategic Sophistication of Individuals and Teams. Experimental Evidence." European Economic Review 64: 395-410.

ThOMSON, KeELA S AND DANIEL M OPPENHEIMER (2016). "Investigating an Alternate Form of the Cognitive Reflection Test." Judgment and Decision Making 11(1): 99-113.

TONG, JoRdAN, DANIEL FeILER ANd ANAStAsia IVANTSOva (2018). "Good Choice, Bad Judgment. How Choice under Uncertainty Generates Overoptimism." Psychological Science 29(2): 254-265.

Toplak, Maggie E, Richard F West and Keith E Stanovich (2014). "Assessing Miserly Information Processing. An Expansion of the Cognitive Reflection Test." Thinking \& Reasoning 20(2): 147-168.

TYKoCINSKI, ORIT E AND ANDREAS ORTMANN (2011). "The Lingering Effects of our Past Experiences. The Sunk-cost Fallacy and the Inaction-inertia Effect." Social and Personality Psychology Compass 5(9): 653-664.

VAN DEN Steen, ERIC (2004). "Rational Overoptimism (and Other Biases)." American Economic Review 94(4): 1141-1151.

van Putten, MariJke, Marcel Zeelenberg ANd ERIC van DiJk (2010). "Who Throws Good Money After Bad? Action vs. State Orientation Moderates the Sunk Cost Fallacy." Judgment and Decision Making 5(1): 33.

ZIZZO, DANIEL JOHN (2010). "Experimenter Demand Effects in Economic Experiments." Experimental Economics 13(1): 75-98. 


\title{
Instructions
}

\author{
treatment variations are marked in yellow
}

\section{Main Experiment}

$<$ Introduction $>$

Feedback from all parts of the experiment is withheld until the very end of the entire experiment.

\section{Part 1}

In this part of the experiment, you a paired with the computer. The computer is programmed to maximize profit.

You and the computer are endowed with 40 ECU (experimental currency units). The computer is additionally endowed with a token. If, at the end of this part of the experiment, the

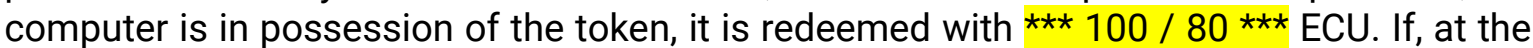
end of this part of the experiment, you are in possession of the token, it is redeemed with $\star \star \star 80 / 100 * \star \star$ ECU.

Either of you (you or the computer) who is currently not in possession of the token can take it. The cost of taking is $\star \star \star$ ECU for you, and $* \star \star E C U$ for the computer.

You and the computer can only take the token if the remainder of your endowment is larger than or equal to the cost of taking.

Any fraction of the endowment of 40 ECU not used for taking is redeemed at the end of the experiment to you or the computer, respectively.

This part of the experiment ends if either the agent currently not in possession of the token declares that she does not want to take, or the remainder of her endowment is smaller than the cost of taking applicable to her.

Whenever the computer is in possession of the token, you will be asked whether you want to take it. Whenever you are in possession of the token, the computer will be asked whether it wants to take it.

\section{Part 2}

Remember: in the first part of the experiment we have explained that the computer maximizes profit. If you yourself had exclusively strived at maximizing profit, which would have been your decision in the first round of the first part of the experiment? Would you have taken the token? If your answer is correct, you earn an additional 20 ECU. 


\section{Part 3}

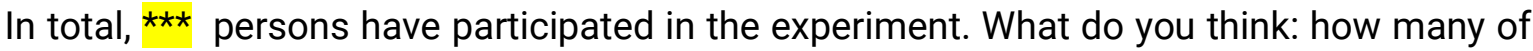
them (you included) have taken the token in the first round of the first part of the experiment? If you get this number exactly right, you earn an additional 20 ECU. If your estimate is no further away from the true number than $+/-2$, you earn an extra 10 ECU.

\section{Supplementary Treatments}

\section{Part 1}

$<$ same as Part 1 of main experiment computer valuation 80 , human valuation 100 , symmetric cost of taking $20>$

\section{(additional) Part 2}

The second part of the experiment has the same structure as the first part. You interact with a computer that is programmed to maximize profit. The computer is initially endowed with one unit of a token. If, at the end of this part of the experiment, the computer is in possession of the token, the computer gets $160 \mathrm{ECU}$. If, at the end of this part of the experiment, you are in possession of the token, you get 200 ECU. You are endowed with $80 \mathrm{ECU}$, which you can use for taking the good (when it is not in your possession). The computer is also endowed with $80 \mathrm{ECU}$, which it can use for taking the good (when it is not in its pos-

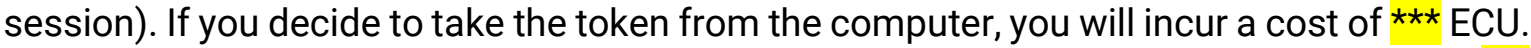

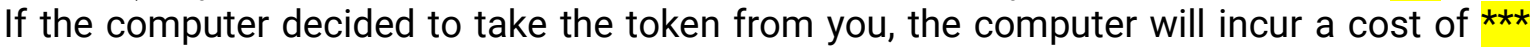
ECU.

\section{Part 3}

<same as Part 2 in the main experiment $>$

\section{Part 4}

<same as Part 3 in the main experiment $>$ 